Original Article

\title{
Analysis of personality traits in patients of road traffic accident (RTA) with special reference to motorcycle riders
}

\author{
Rahul Goyal $^{a}$, Vineet Kumar ${ }^{b}$, Kumar Shantanu $^{b}$, Shah Walliullah ${ }^{b}$, \\ Shailendra Singh ${ }^{b}$, Ajai Singh ${ }^{c, *}$ \\ a Junior Resident, Department of Orthopaedic Surgery, King George's Medical University, Lucknow, Uttar Pradesh 226 \\ 018, India \\ b Assistant Professor, Department of Orthopaedic Surgery, King George's Medical University, Lucknow, Uttar Pradesh \\ 226018 , India \\ c Professor, Department of Orthopaedic Surgery, King George's Medical University, Lucknow, Uttar Pradesh 226018 , India
}

\section{A R T I C L E I N F O}

Article history:

Received 15 September 2015

Accepted 30 October 2015

Available online 28 November 2015

Keywords:

Road traffic accident (RTA)

Personality traits

Motorcyclist

\begin{abstract}
A B S T R A C T
Background: Road traffic accidents (RTAs), in the current scenario, have taken the form of an epidemic. Developing countries are presently showing an increasing trend with respect to the number of vehicles and population. Personality characteristics are becoming a significant contributor in RTAs, owing to rising stress levels and varying circumstances. Patients and methods: A total of 250 cases and 210 controls of age $>18$ years were selected, as per criteria decided. After primary management and obtaining clearance from the institutional ethical committee, all enrolled subjects were assessed by International Personality Disorder Examination (IPDE) - ICD 10 module screening questionnaire and analyzed for nine personality traits.

Results: Of all the cases enrolled, 72.8\% were males. There were 81 motorcyclists out of 250 cases enrolled. Amongst all the motorcyclists encountering RTA, impulsive personality trait is found in $85.19 \%$ and histrionic trait was found in $82.72 \%$ of cases.

Discussion: Motorcycle riders having impulsive and histrionic personality characteristics constitute $32.4 \%$ of RTA victims, attending orthopedics emergency unit at trauma center of a tertiary care center were, the presence of which was statistically significant.
\end{abstract}

(C) 2015 INDIACLEN. Published by Elsevier, a division of Reed Elsevier India, Pvt. Ltd. All rights reserved.

\section{Introduction}

Accident is defined as a sudden occurrence in a sequence of events, which usually produces unintended injury, death, or property damage. Road traffic accident (RTA) continues to constitute a major bulk of noncommunicable diseases in the present era. ${ }^{1}$ As per available records of World Health Organization, road crashes dominate this category of injuries worldwide and constitute around $25 \%$ of all moralities. ${ }^{2}$ It is

\footnotetext{
* Corresponding author. Tel.: +919415022557.

E-mail address: as29762@gmail.com (A. Singh).

http://dx.doi.org/10.1016/j.cegh.2015.10.010

2213-3984/C 2015 INDIACLEN. Published by Elsevier, a division of Reed Elsevier India, Pvt. Ltd. All rights reserved.
} 
projected that RTAs will be the 5th leading cause of death, overtaking diabetes and human immunodeficiency virus infection/acquired immunodeficiency syndrome by the year 2030 , taking into consideration its current incidence and rate. ${ }^{3}$

In our country (India), according to the latest report of the National Crime Records Bureau, it is expected that mortality due to RTA figures to 13 people every hour, which is a major contributor to misery, disability, and deaths in our country, as well as worldwide, with a disproportionate number occurring in developing countries. ${ }^{4-6}$ It is estimated that by 2020, RTAs will probably rank as high as third among the causes of disability-adjusted life years lost. ${ }^{6-8}$ In developing countries, most of the RTAs occur in urban regions and pedestrians, passengers, and motorcyclists collectively constitute around $90 \%$ of deaths. This increased frequency of distribution for accidents in developing countries cannot be attributed to chance alone. 8

Different individuals may behave differently to a given situation or under common circumstances, which probably is because of an individual's personality trait. The recent concept emphasizes the role of temporary life stresses in causing personality deterioration in individual and thus leading to accidents. Personality of an individual is basically a moderator between stimuli and behavior. The answer as to why people in similar situations act differently is probably explained by an individual's personality trait. It is hypothesized that, if differences in personality characteristic of cases in RTA patients are identified, it could then be correlated to its accident proneness. We, therefore, conducted this study in order to evaluate the patterns of various personality characteristics in patients suffering from nonfatal orthopedic injuries as a result of RTA and attending a tertiary care center, with special focus on motorcyclists.

\section{Material and methods}

We carried out this study on fully conscious and oriented patients of $>18$ years, suffering from nonfatal orthopedic injuries, as a result of RTA, and attending Orthopedics Emergency Unit, Trauma Center of a tertiary care center during April 2014 to March 2015. The patients not having any significant psychiatric illness, ${ }^{9}$ as per the history and treatment records, and giving informed consent were selected as cases. The attendants of the cases with similar socioeconomic profile except injury were taken as controls. This study was a hospital-based open-ended exploratory study with 250 cases and 210 controls.

After the ethical approval from institutional ethical committee and written informed consent, all cases were clinically assessed and managed. Thereafter, all the cases and controls satisfying our inclusion-exclusion criteria were given a personality assessment questionnaire, which was an International Personality Disorder Examination ICD-10 Module Screening Questionnaire. ${ }^{10}$ The injury assessment of cases was done by injury severity score (ISS). ${ }^{11}$ Nine personality characteristics diagnosed in response to screening questionnaire were studied in both cases and controls and association of any of these characteristics with RTA (especially motorcycle drivers) was evaluated for statistical significance. All the statistical tests were performed with graph pad prism 5.0 software.

\section{Results}

In this study, we registered a total of 250 cases and 210 controls, as per inclusion-exclusion criteria. In our study, there were $72.8 \%$ males (182/250). In our study population, the mean age of cases was $35.32 \pm 2.75$ (range 31-40) and that of controls was $35.45 \pm 2.85$ (range 31-40). Of all cases, 39.2\% were motorcyclists $(98 / 250)$ belonging to $31-40$ years age group (76/250; 30.4\%). On considering the educational status of our study population, the majority of cases (38.8\%) and controls (44.2\%) were 10th standard passed followed by those who were 5 th standard passed ( $23.6 \%$ cases and $23.8 \%$ controls). Only $10.4 \%$ cases and $6.6 \%$ controls were graduate and above. There was no statistical significant difference observed in educational status between both cases and controls (Table 1).

In occupational status, majority of cases (42.8\%) and controls (43.3\%) were laborers followed by farmers $(39.2 \%$ cases and $40.9 \%$ controls). Only $18.0 \%$ cases and $15.6 \%$ controls belonged to professional and self-employed group. There was no statistical significant difference in occupational status of cases and controls (Table 1).

Fractures constitute $92 \%$ (230/250) of all injuries, of which $62.4 \%(156 / 250)$ were closed, with AO subtype 42A having most frequent occurrence. Of all the open injuries ( $n=105), 44.76 \%$ $(47 / 105)$ were Gustilo grade 2. Various personality traits in

Table 1 - Educational and occupational status of RTA cases and control subject.

\begin{tabular}{|c|c|c|c|c|}
\hline & \multirow[t]{2}{*}{ Description } & \multicolumn{2}{|c|}{ Number (\%) } & \multirow[t]{2}{*}{$P$ value } \\
\hline & & Cases $(n=250)$ & Controls $(n=210)$ & \\
\hline \multirow[t]{6}{*}{ Educational status } & Never gone school & $45(18.0)$ & 34 (16.2) & \multirow[t]{6}{*}{$X^{2}=2.353, P=0.7984$} \\
\hline & $<6$ th Standard & $59(23.6)$ & $50(23.8)$ & \\
\hline & 6-10th standard & $97(38.8)$ & $93(44.2)$ & \\
\hline & $>10-12$ th standard & $25(10.0)$ & $19(09.0)$ & \\
\hline & Graduate & $10(04.8)$ & $06(02.8)$ & \\
\hline & Post-graduate & $14(05.6)$ & $08(03.8)$ & \\
\hline \multirow[t]{4}{*}{ Occupational status } & Farmer & 98 (39.2) & $86(40.9)$ & \multirow[t]{4}{*}{$X^{2}=1.481, P=0.6865$} \\
\hline & Laborer & $107(42.8)$ & $91(43.3)$ & \\
\hline & Professional & $23(09.2)$ & $13(06.1)$ & \\
\hline & Self-employed & $22(08.8)$ & $20(09.5)$ & \\
\hline
\end{tabular}


Table 2 - Personality characteristics of RTA cases and control subject.

\begin{tabular}{|c|c|c|c|c|c|c|c|c|c|}
\hline $\begin{array}{l}\text { Personality } \\
\text { characteristics }\end{array}$ & $\begin{array}{c}\text { Pedestrian } \\
(58)\end{array}$ & $\begin{array}{c}\text { Passenger } \\
(41)\end{array}$ & $\begin{array}{c}\text { Motorcyclists } \\
(81)\end{array}$ & $\begin{array}{l}\text { LMVD } \\
(21) \\
\end{array}$ & $\begin{array}{c}\text { HMVD } \\
(49)\end{array}$ & $\begin{array}{l}\text { Total number } \\
\text { of cases (250) }\end{array}$ & $\begin{array}{c}\text { Percentage } \\
\text { of cases }\end{array}$ & $\begin{array}{c}\text { Number of } \\
\text { controls (210) }\end{array}$ & $\begin{array}{l}\text { Percentage } \\
\text { of controls }\end{array}$ \\
\hline Paranoid & 40 & 23 & 49 & 11 & 16 & 139 & $55.63 \%$ & 84 & $40.18 \%$ \\
\hline Schizoid & 18 & 5 & 5 & 2 & 5 & 35 & $14.08 \%$ & 43 & $20.53 \%$ \\
\hline Dissocial & 30 & 9 & 60 & 10 & 39 & 148 & $59.15 \%$ & 54 & $25.89 \%$ \\
\hline Impulsive & 40 & 21 & 69 & 14 & 26 & 171 & $68.31 \%$ & 54 & $25.89 \%$ \\
\hline Borderline & 30 & 14 & 49 & 14 & 25 & 132 & $52.82 \%$ & 45 & $21.43 \%$ \\
\hline Histrionic & 37 & 23 & 67 & 16 & 24 & 167 & $66.90 \%$ & 47 & $22.32 \%$ \\
\hline Anankastic & 21 & 7 & 26 & 4 & 7 & 65 & $26.06 \%$ & 74 & $29.46 \%$ \\
\hline Anxious & 16 & 11 & 25 & 5 & 12 & 69 & $27.46 \%$ & 146 & $69.64 \%$ \\
\hline Dependent & 12 & 14 & 11 & None & 9 & 46 & $18.31 \%$ & 107 & 50.89 \\
\hline
\end{tabular}

cases and controls were assessed with the help of standard screening questionnaire and their frequency of occurrence was recorded (Table 2). We observed that both the cases and controls had multiple personality traits. From RTA analysis done in our study, of all cases attending orthopedics emergency unit at trauma center, $68.31 \%$ were having impulsive and $66.90 \%$ histrionic personality trait, which accounted for the majority of cases, whereas in controls, $69.64 \%$ individuals were having anxious personality trait (most common). Impulsiveness and histrionic traits were relatively rarer in controls.

On analyzing the personality traits in motorcyclists encountering RTA by applying chi-square test (Table 3), we found that histrionic, impulsive, and dissocial traits were shown to have a statistical significant association with RTA amongst cases and controls, i.e. these traits are pro-accident in nature whereas cases with schizoid, anankastic, anxious, and dependent traits showed a statistical negative association, meaning thereby that these traits are protective in nature, and thus preventing RTAs in motorcyclists, as they are seen significantly more common in controls. Paranoid and borderline personality characteristics were not significantly associated with motorcyclist RTA victims.

\section{Discussion}

It has been well propagated that "man drives as he lives," and this is pretty obvious from the fact that the more an individual

Table 3 - Personality characteristics of motorcyclists, who are RTA victims.

\begin{tabular}{lcccc}
$\begin{array}{l}\text { Personality } \\
\text { characteristics }\end{array}$ & Present & Absent & Percentage & P-value \\
\hline Paranoid & 49 & 32 & $60.49 \%$ & 0.1586 \\
Schizoid & 5 & 72 & $6.49 \%$ & 0.001 \\
Dissocial & 60 & 21 & $74.07 \%$ & 0.0006 \\
Impulsive & 69 & 12 & $85.19 \%$ & 0.0010 \\
Borderline & 49 & 32 & $60.49 \%$ & 0.1586 \\
Histrionic & 67 & 14 & $82.72 \%$ & 0.0010 \\
Anankastic & 26 & 54 & $32.5 \%$ & 0.0146 \\
Anxious & 25 & 57 & $30.49 \%$ & 0.0056 \\
Dependent & 11 & 73 & $13.09 \%$ & 0.0010 \\
\hline
\end{tabular}

has problems related to personal and social demands of living, the more he tends to make driving errors. ${ }^{12}$ RTAs are inevitable, but we can definitely make some positive attempts to reduce its incidence to the bare minimum. In accordance to the above, it has been observed that many a times there is a disproportionate distribution of accidents among drivers with similar exposure. It might be merely due to chance, but this is what we describe as accident proneness. On this basis, a model has been hypothesized, "Accident Proneness Model", the proponents of which emphasize that personality traits rather than individual differences in psychomotor ability determine which individuals are more prone to accidents when the exposure risk is equal. This model has the implication that a comparatively small group of individuals is responsible for the majority of accidents, for which there has to be a reason.

There are some major factors in RTAs or the traffic phenomenon, which needs a special consideration, i.e., quality of motives, feelings, attitudes, beliefs and value system, and a set of individual and social behaviors. In this context, conditions governing the driver's cognitive field and their emotional, behavioral, and sensory-motor feelings, along with their personality and psychological characteristics, could possibly play a role in traffic and traffic accidents. There are certain documented elements of psychological factors playing an important role in law-breaking behaviors of drivers, including the personality traits, such as impulsiveness affectivity, extraversion, individual differences, and social and attitudinal factors. ${ }^{13}$

In motor vehicle drivers, personality characteristics of impulsivity and adventurousness, aggressiveness, inability to tolerate authority and control hostility, being indifferent to the rights of others, preoccupation with fantasy of satisfaction, fear of loss of love and support, inability to tolerate tension, poor self-control, and guilt-proneness have been reported to occur frequently. ${ }^{14}$ We hypothesized that individual personality traits have a significant association with RTA in motorcyclists.

In our study, on analysis we found that maximum number of cases was of motorcyclists. This is probably due to the fact that we are a developing nation with a huge population having motorized two wheeler vehicles as a major means of private transport. Also, these motorized two wheelers have a low safety profile that makes their riders more prone to accident. 
As far our literature-based knowledge goes, there has been no study done till date in reference to this parameter of our study. Previously, there have been evidences, mentioning correlation of various personality traits and behavior with many other aspects of RTAs and accident proneness.

Jonah et al., ${ }^{13}$ in their meta-analysis of 40 studies, came to a conclusion that high-sensation seeking patients were more likely to experience collisions and violations than lowsensation seekers. We have used IPDE ICD-10 module screening questionnaire in our study, which is an international module. The Hindi version of ICD-10 IPDE has acceptable joint-rater reliability and applicability in the North Indian Hindi speaking population. ${ }^{15}$ This module screening questionnaire does not include sensation seeking as a personality trait. In our study, persons with impulsiveness and histrionic personality traits were found to be more prone to RTA, as is seen in motorcyclists, probably due to loss of self-control. Histrionic trait in our module, being defined as a melodramatic behavior designed to attract attention, is comparable to sensation seeking behavior. Thus our study findings are in accordance with and are supported by the study conclusion of Jonah et al. Our study is also supported by Blanchard et al., ${ }^{16}$ who analyzed amongst different personality traits that sensation seeking trait is a good predictor of self-reported driving violations.

Apprehension was described as a protective trait in cases with RTA by Manglam et al. ${ }^{17}$ whereas anxiety as a trait in our study also revealed a negative association with RTAs, and anxiety in a way pertains to apprehension.

A vast majority of motorcyclists in our study, who are RTA victims, have predominance of impulsive and histrionic personality characteristics accounting for $84.78 \%$ and $82.61 \%$ cases, respectively. Our study is supported by the study findings of Beirness, ${ }^{18}$ who concluded reduced capacity to manage or control hostility as a major factor accounting for crash injuries in RTAs. This pertains in our study to be having an impulsive personality trait, and they are prone to RTAs. He also analyzed that the subgroup characterized by aggressive and unsocialized tendencies encountered the greatest numbers of traffic accidents.

Based on the observations from our study, we can make an effort to scrutinize these people (those having personality characteristics, which are more prone for RTAs) for proper counseling. This can be of vital importance in understanding RTA prevalence and to further reorient our planning in order to keep a check on increasing incidence of RTA. This will certainly help in reducing the extra burden on health policy makers and healthcare providers.

Conclusive strength of our study is limited by its small sample size. Multicentric studies with larger sample size are further needed to gather strong support and valid justification in favor of the above evidences generated in our study. We would definitely like to stress upon the fact that the causation of RTA is multifactorial, and in this study, we have focused only on one aspect (personality trait) of it, which might be one of the possible associations and should not definitely be attributed as a sole cause for it.

\section{Conflicts of interest}

The authors have none to declare.

\section{R E F E R E N C E S}

1. Park JE. Textbook of Preventive and Social Medicine. A Treatise on Community Health. Banarsidas Bhanot, University of Michigan; 1970

2. Peden M, McGee K, Sharma G. The Injury Chart Book: A Graphical Overview of the Global Burden of Injuries. Geneva: World Health Organization; 2002 http://whqlibdoc.who.int/ publications/924156220X.pdf?ua=1 [accessed on 12.07.15].

3. National Crime Record Bureau. Annual Report on Accidental Deaths and Suicides in India. 2010 http://ncrb.gov.in/ADSI2010/ ADSI2010-full-report.pdf [accessed on 15.07.15].

4. Tiwari G, Mohan D, Muskang R. Mumbai Urban Transport Project 2: Accident Study. 1-342. Final Report Prepared for World Bank. New Delhi: TRIPP, Indian Institute of Technology Delhi; 1998.

5. Nantulya VM, Reich MR. The neglected epidemic: road traffic injuries in developing countries. BMJ. 2002;324:1139-1141.

6. Lagarde E. Road traffic injury is an escalating burden in Africa and deserves proportionate research efforts. PLoS Med. 2007;4(6):e170.

7. Ghaffar A, Hyder AA, Masud TI. The burden of road traffic injuries in developing countries: the first national survey of Pakistan. Public Health. 2004;118(3):211-217.

8. Museru LM, Leshabari MT. Road traffic accidents in Tanzania: a 10-year epidemiological appraisal. East Cent Afr J Surg. 2002;7(1):23-26.

9. Stein DJ, Phillips KA, Bolton D, Fulford KWM, Sadler JZ, Kendler KS. What is a mental/psychiatric disorder? From DSM-IV to DSM-V. Psychol Med. 2010;40(11):1759-1765.

10. Loranger AW, Aleksandar J, Norman S. Assessment and Diagnosis of Personality Disorders: The ICD-10 International Personality Disorder Examination (IPDE). Cambridge University Press; 1997.

11. Baker SP, O'Neill B, Haddon W, Long WB. The Injury Severity Score: a method for describing patients with multiple injuries and evaluating emergency care. J Trauma. 1974;14(3):187-196.

12. Feldman MP. Man drives as he lives - psychological factors in road accidents. Automob Eng. 1967;508-509.

13. Jonah B. Sensation seeking and risky driving: a review and synthesis of the literature. Accid Anal Prev. 1997;26(3):217-223.

14. Tillmann WA, Hobbs GE. The accident prone automobile driver; a study of the psychiatric and social background. Am J Psychiatry. 1949;106(5):321-331.

15. Sharan P, Kulhara P, Verma SK, Mohanty M. Reliability of the ICD-10 International Personality Disorder Examination (IPDE) (Hindi Version): a preliminary study. Indian J Psychiatry. 2002;44(4):362-364.

16. Blanchard EB, Barton KA, Malta L. Psychometric properties of a measure of aggressive driving: the Larson Driver's stress profile. Psychol Rep. 2000;87(7):881-892.

17. Manglam MK, Sinha VK, Praharaj SK, Bhattacharjee D, Das A. Personality correlates of accident-proneness in auto-rickshaw drivers in India. Int J Occup Saf Ergon. 2013;19(2):159-165.

18. Beirness DJ. Do we really drive as we live? The role of personality factors in road crashes. Alcohol Drugs Driv. 1993;9 (4):129-143. 